\title{
Vaccination and deworming of foals: Owners' perspective
}

\author{
Heli I. Koskinen
}

University of Helsinki, Finland

\begin{abstract}
Foals are susceptible to many infectious diseases and they should be treated and protected differently compared to adult horses. Objectives of this study were to investigate vaccination and deworming practices of foal owners in Finland. The questionnaire study was executed. Foal owners $(n=236)$ gave a response and 217 of them told that they vaccinate their foals against equine influenza and tetanus (combination vaccine) (88\%) and herpes (12\%), but not against rabies (1,8\%). About $8 \%$ did not vaccinated their foal at all and a risk of being non-vaccinated was regionally distributed (p<0,05). Among foal owners deworming (99,2\%) preferred over vaccination (92\%). Foals were dewormed by taking regular fecal samples first (76\%), but also routine treatments without samples were favored (22 \%). Differences between foals of this study and horse population in general (horses of all ages) need to take seriously when conclusions are drawn. Different recommendations come from different veterinarians should be taken under further research.
\end{abstract}

Keywords-equine influenza; deworming; foal; survey; vaccination.

\section{INTRODUCTION}

Foals are especially susceptible to many infectious diseases. During their first weeks or months of life they encounter infectious agents such as Rhodococcus equi, rota virus and $E$. coli which are rare or less threatening among adult mature horses. Therefore, protection of the foal against specific infectious diseases that it is likely to encounter during the first few months of life, as its own immune system matures, relies heavily on postnatal absorption of specific antibodies and perhaps other factors that the dam has concentrated in colostrum during late gestation (Wilson et al., 2014). In general, vaccination of foals under six months of age is not recommended because maternal antibodies have been shown to exert a profound inhibitory effect on the immune response of foals to antigens, including those contained in vaccines. Foals less than six months of age consistently failed to mount serologic responses to inactivated influenza vaccines (van Maanen et al., 1992; Cullinane et al., 2001; Wilson et al., 2010) and cattle vaccines (Ryan \& Giguére, 2010). In contrast, young horses can show increased cytotoxic cellular immune responses by modified-live herpes vaccines despite the presence of maternal antibodies (Ellis et al., 1997), and especially when 3-dose series with a multivalent vaccine are administered (Davis et al., 2015)
Most foals develop permanent immunity against Strongyloides not until by five or six months of age (Nielsen et al., 2014). On the other hand, it was found among thoroughbred foals that Strongyle counts increase and ascarid counts peak at 4,5 -5 months of age (Bellaw et al., 2016). Thus, in addition to external infectious diseases foals are threatened by internal parasites. Foal owners should comply deworming instructions recommended by their own veterinarian. As a result from one study among foals, the use of combination therapy of ivermectinpyrantel against small strongyles and parascaris has been recommended (Luksovsky et al., 2013). Various drugs and drug combinations have been used among foals in Finland (Näreaho et al., 2011) and because of observed increase in anthelmintic resistance among horse population worldwide, it is recommended by Finnish veterinary practitioners that the efficacy of anthelmintic should be tested by taking fecal samples before and after the grazing season (Recommendation of Finnish Veterinary Practitioners, 2019; Horse Information Centre of Finland, 2019). Among foals, test results influence on only the choice of the anthelmintic and foals need to deworm in any case, regardless of the test results.

A consensus on current best deworming practice should achieve because there are many insufficient measures to reduce the development and spreading of anthelmintic 
resistance (Rendle et al., 2019). In Denmark, certain groups of horses such as foals, horses less than three years of age, pregnant mares and horses with clinical signs of parasitic diseases are treated with anthelmintics by $95 \%$ of veterinarians without prior fecal analysis (Nielsen et al., 2006). Also horse owners' practices should be improved. Study from Italy shows that $85 \%$ of horse owners do not ask for prior fecal examination and horses are routinely (94 $\%$ ) and massively (61\%) dewormed (Papini et al., 2015). Similarly, Swedish horse owners told that only $1 \%$ of them perform fecal egg counts on a regular basis (Lind et al., 2007). In Thoroughbred trainers in England not always based their choice of anthelmintic on veterinary advice (Earle et al., 2002) and in England, Scotland, Wales and Ireland many owners do not follow parasite recommendations available (Lloyd et al., 2000; Stratford et al., 2014; Elghryani et al., 2019). In contrast in Germany, both regular deworming management and selective anthelmintic therapy with less deworming times per year have been introduced (Simoneit et al., 2018).

In Finland it is estimated in one study that $85-95 \%$ of horses are vaccinated at least against equine influenza (Koskinen, 2014a). However, foals below the recommended vaccination age in Finland (from five to seven months) were well represented in this survey and nothing is known about the vaccination of all foals (under 12 months of age). Risk factors for parasitic infections such as pasture hygiene and hygiene routines of housing (Aromaa et al., 2018), and farm size and frequency of horse movements (Hautala et al., 2019) have been revealed in Finnish conditions, but the internationally comparable study of deworming practices is neglected. The objective of this study is to investigate vaccination and deworming practices of foal owners in Finland. The goals are to complete previous vaccination study (Koskinen, 2014a) by the second questionnaire and to add worm control information for Finnish authorities.

\section{MATERIALS AND METHODS}

\section{Questionnaire}

Questionnaire of this study was based on previous survey among Finnish horse owners (Koskinen, 2014a) with some modifications. Questions were the responsibility of the author and a layout of current questionnaire was designed with collaboration of research center Kantar TNS (former Gallup of Finland). As background data geographical location of a foal home stable (Southern, Northern, Eastern, Western part of Finland or a foreign country), breed of a foal (thoroughbred, half-breed, warmblooded/trotter horse, Finnish horse, pony or other), a number of foals per an owner and a number of horses in foal's home stable (under of over 10) were included. A basic questionnaire was based on both vaccination and deworming questions (Table 1) with recent recommendations given by Finnish Food Authority (Finnish Food Authority, 2019), Finnish Veterinary Practitioners (2019) and Horse Information Centre of Finland (2019). In the introduction section of the questionnaire owners were invited to take foal's passport close to their eyes before starting the survey because all of vaccination entries can be found in this passport.

\section{Table 1 Survey questions}

At what age I have vaccinated/will vaccinate my foal (several alternatives possible)

How many times I will vaccinate/have vaccinated my foal (several alternatives possible)

I will vaccinate/have vaccinated my foal against a) equine influenza (Equilis prequenza, Equip F, Duvaxyn IE Plus, ProteqFlu), b) against tetanus (Equilis, Tetanus), c) both against equine influenza and tetanus (Equip FT, ProteqFlu TE, Duvaxyn IE-T Plus, Equilis prequenza TE), d) against herpes rhinopneumonitis (Duvaxyn EHV 1,4, Equilis resequin, Equip EHV 1,4), e) against rabies (Rabdomun, Rabisin) (several alternatives possible)

I will vaccinate/have vaccinated my foal according to this recommendation

I will vaccinate/have vaccinated my foal according to the recommendations of the Finnish Trotting and Breeding Association (trotters in competitions)

I will vaccinate/have vaccinated my foal according to the recommendations of the Equestrian Federation of Finland (riding horses in competitions)

I will vaccinate/have vaccinated my foal according to the other recommendation

I do not vaccinate my foal

At what age I have dewormed/will deworm my foal (several alternatives possible)

How many times I have dewormed/will deworm my foal (several alternatives possible)

I will deworm/have dewormed my foal according to these recommendations, or one of them

I will deworm/have dewormed my foal according to the other recommendation (e.g. by using the old way in which all horses in stable will have been treated routinely)

I do not deworm my foal according this recommendation/these recommendations 


\section{Questionnaire distribution}

In Finland, all foals must be registered in the Finnish Trotting and Breeding Association (Suomen Hippos) as soon as possible and within six months after birth. Firstly, announcement of birth must be submitted and secondly, identification process must be promoted. Thus, Suomen Hippos has a register of personal data such as contact details of foal owners, and before a distribution of the questionnaire, an agreement of transfer and utilization of personal data was to be obtained between Suomen Hippos and Kantar TNS.

This study was focused on foals, which meant horses under 12 months of age. In 2018, 2942 foals were born in Finland (The Finnish Trotting and Breeding Association (2019). For this survey, all foals born in 2019 were included. After the contract between Suomen Hippos and Kantar TNS had been concluded it was a duty of Kantar TNS to send phone messages or e-mails to foal owners and two reminder messages to those with no response. In total, invitations were sent to 1799 phone numbers. The survey was conducted in December 2019, at a time when vaccination of first foals of spring 2019 has begun (among six or seven months of age). The survey was coded and launched in early December before Christmas and respondents were given two weeks to reply.

\section{Data analysis}

Based on preliminary variable frequency tables with only a few observations in some background categories, such as a location (Northern part of Finland and a foreign country) and a breed (thoroughbred), these categories were modified. New categories of geographical location (Southern, Eastern and Western part of Finland or other location) and a breed (half-breed, warm-blooded/trotter horse, Finnish horse, pony or other) were established. For further statistical data analysis, SPSS statistics for Windows, version 25.0 (IBM Corp, Armonk, NY) was used. Vaccination and parasite control questions, classified into their own categories, were kept separated in logistic regression analysis. In this analysis, only first foal from each owner (if there were several foals) was included and odds ratios (OR) with lower and upper $95 \%$ confidence intervals (CI) were calculated. This removal of second and following foals was due to an attempt to ensure that the foals had different owners and therefore, were independent of each other. The probability of being no vaccinated between categories of the explanatory variable was analyzed and as a result, one-variable regression model was achieved.
Overall, 236 responses were received. The number of foals among these owners varied between one to 16 , being on average of 1,6 foals per owner (74\% had only one foal). All breeds were found albeit Finnish horses (35\%), warmblooded/trotter horses (29\%) and half-breeds (20\%) were best represented. The foals were mainly located in Western Finland (39\%) in small (under 10 horses) stables (66\%) and they were almost all vaccinated and dewormed. Only two of these foals $(0,8 \%)$ were left without anthelmintic treatment and $19(8 \%)$ were not vaccinated.

Because only two foals left without anthelmintic treatment, the probability of being no dewormed between categories of the explanatory variable could not be calculated. Instead, related to vaccinations it was found that in Eastern Finland there was fivefold increased risk of being without vaccines compared to reference category Southern Finland $(\mathrm{OR}=5,37, \mathrm{p}<0,05), 95 \% \mathrm{CI}(1,07,27,08)$. All halfbreed foals were vaccinated $(100 \%)$. Although the vaccine coverage left under 100 percent among other breeds, there were no significant $(\mathrm{p}<0,05)$ differences between breeds ( $p=0,052$ between warm-blooded/trotter horses and Finnish horses).

Foal owners were unanimous in the importance of certain vaccines. Equine influenza vaccine with tetanus vaccine (combination vaccine) was given to foals with high level of coverage $(192 / 217,88 \%)$. Surprisingly, also herpes virus vaccine was favored $(27 / 217,12 \%)$. On the other hand, rabies vaccine was almost totally ignored (4/217, 1,8\%) and $14(6,5 \%)$ of the owners did not know or could not say their opinion. The majority of foals were vaccinated at six months of age $(125 / 217,58 \%)$ and at a time of the survey the foals had received $1-3$ vaccinations $(92+78+41 / 217$, $97 \%)$. The majority of the owners complied with the recommendation of Finnish Food Authority (131/217, 60 $\%)$ when they vaccinate their foals. In addition, the recommendations of the Equestrian Federation of Finland and recommendations of the Finnish Trotting and Breeding Association were followed $(49 / 217,23 \%$ and 33/217, 15 $\%$ respectively).

The majority of foal owners complied with deworming recommendations in which fecal sampling was included $(177 / 234,76 \%)$. The old way with routine treatments or other recommendation were also supported (52/234, $22 \%)$. At a time of the survey the foals had received at least one anthelmintic treatment $(19 / 234,8 \%)$, but most commonly, three treatments $(98 / 234,42 \%)$. Majority of the foal owners gave the first anthelmintic treatment at two months of age $(166 / 234,71 \%)$, but also a practice with four or six months of age was observed (148/234, $63 \%$ and 149/234, $64 \%$, respectively).

\section{RESULTS}


Below one $(<1)$ OR estimates were seen when values between deworming recommendations and an old routine anthelmintic treatment was calculated. They were not statistically significant $(\mathrm{OR}=0,4, \mathrm{p}=0,063$ in Eastern Finland compared to reference category Southern Finland) and thus, an increased risk of using old routine treatment cannot be demonstrated. Respectively, with no significant analysis result $(\mathrm{p}=0,083)$, non-vaccination of a foal cannot be explained by non-deworming of a foal or vice versa, although a high OR estimate (12) between them was revealed.

\section{DISCUSSION AND CONCLUSIONS}

The foals of this study are for the most part vaccinated and dewormed (92\% and 99,2\%, respectively). The majority of the owners complied with recommendations regarding current vaccination and deworming practices. However, these respondents are these foal and horse owners who see the importance of vaccination and fecal sampling before anthelmintic treatment. They also know how to answer (the correct answers from the researcher's perspective). On the other hand, they may not have experiences with vaccine side effects regarding their own equine; an important reason for non-vaccination of horses in previous studies (Koskinen, 2014a; Goyen et al., 2017) or they might have thought that despite the side effects vaccination is necessary for a good life of a foal. In Finland, it has been found that $85-95 \%$ of horses of all ages are vaccinated depending on the number of horses per an owner (Koskinen, 2014a), so it can be estimated that the percentage shown here $(92 \%)$ is on the same line.

Survey results $(92 \%)$ were based on calculations in which only first foal from each owner (if there were several foals) was included. Estimation of $92 \%$ is comparable to the highest vaccination level (95\% coverage score) among those horses, which owners have only one horse (Koskinen, 2014a) and the results that handling of more than three horses per week is a risk factor for nonvaccination (Goyen et al., 2017). Vaccination may become a cost issue when the number of horses increases. In addition to the owners' concerns about vaccine safety and effectiveness, in the list of reasons for non-vaccination costs are emphasized (Manyweathers et al., 2017).

Deworming responses among foal or horse owners has never before been collected in Finland and thus, it is difficult to say whether the high coverage of anthelmintic treatments in the current study can be generalized to the whole horse population. In addition, foals should be treated differently than mature horses. However, due to increasing resistance, also observed in Finland (Näreaho et al., 2011;
Hautala et al., 2019), it is worrying that almost a quarter of the foal owners use anthelmintic against parasites without sampling and without a worry of increasing resistance. Based on the results of this study, the foal owners could be expected to be much more critical in using vaccines than in using anthelmintics. Perhaps the owners have not been sufficiently informed on reduced efficiency of anthelmintic medication and adverse effects of anthelmintic products.

Foal owners in Eastern Finland left more likely their foals unvaccinated compared to foal owners in Southern Finland. There are also long distances between horse stables in Eastern Finland (and lower horse density), compared to stables in Southern Finland and thus, fewer contacts between horses come from different venues. In one previous Finnish study (Koskinen, 2014b) differences between vaccinations (or vaccination markings) were found when geographical factors (Southern vs. Northern) were taken seriously so the difference between regions is not surprising. In this study, regional differences in use of anthelmintics (yes or no) could not be calculated, but in the next study, the prevalence of different worms in different regions should be compared to the use of anthelmintics and to the different instructions that veterinarians give to their customers. The prevalence of tapeworm infections in Finland, for example and the importance of tapeworms and deworming against tapeworms in horse population in general stimulates discussion from time to time. Some veterinarians believe that horses are not affected with tapeworms at all because the infection prevalence of tapeworms is low. It would be interesting to know, how opinions of veterinarians differ between different regions.

As a conclusion, by vaccination protocols of foal owners a herd immunity is induced. Secondly, a trend towards a more responsible anthelmintic use approach can be seen. The situations is not the same as in the early 2000s when many owners do not comply with medication recommendations (Lloyd et al., 2000; Earle et al., 2002) or a practice of veterinarians to give anthelmintics to large group of horses without prior fecal analysis (Nielsen et al., 2006). Most Finnish foal owners do not favor routine and massive anthelmintic control practice, still common in Italy in 2015 (Papini et al., 2015), but are closer to Scottish and German practice with fecal egg count analysis, reduced treatment frequency and selective anthelmintic therapy (Stratford et al., 2014; Simoneit et al., 2018). It may be due to increased knowledge of anthelmintic resistance or cultural change in the use of medicines in general. 


\section{ACKNOWLEDGEMENTS}

The Author thanks the Finnish Trotting and Breeding Association, and all the individuals who participated in this survey. She has no declared no conflict of interests. She has no source of funding.

\section{CONFLICT OF INTERESTS}

The Author has no conflict of interests.

This research did not receive any specific grant from funding agencies in the public, commercial, or not-forprofit sectors.

\section{REFERENCES}

[1] Aromaa, M., Hautala, K., Oksanen, A., Sukura, A., Näreaho, A. 2018. Parasite infections and their risk factors in foals and young horses in Finland. Vet. Parasitol. Reg. Stud. Reports. 12, 35-38.

[2] Bellaw, J.L., Pagan, J., Cadell, S., Phethean, E., Donecker, J.M, Nielsen, M.K. 2016. Objective evaluation of two deworming regimens in young thoroughbreds using parasitological and performance parameters. Vet. Parasitol. 221, 69-75.

[3] Cullinane, A., Weld, J., Osborne, M., Nelly, M., Mcbride, C., Walsh, C. 2001. Field studies on equine influenza vaccination regimes in thoroughbred foals and yearlings. Vet. J. 161, 174-185.

[4] Davis, E.G., Bello, N.M., Bryan, A.J., Hankins, K., Wilkerson, M. 2015. Characterisation of immune responses in healthy foals when a multivalent vaccine protocol was initiated at age 90 or 180 days. Equine Vet J.47, 667-674.

[5] Earle, C.G., Kington, H.A., Coles, G.C. 2002. Helminth control used by trainers of thoroughbreds in England. Vet. Rec. 150, 405-408.

[6] Elghryani, N., Duggan, V., Relf, V., de Vaal, T. 2019. Questionnaire survey on helminth control practices in horse farms in Ireland. Parasitol. 146, 873-882.

[7] Ellis, J.A., Steeves, E., Wright, A.K., Bogdan, J.R., Davis, W.C., Kanara, E.W, et al. 1997. Cell-mediated cytolysis of equine herpesvirus-infected cells by leukocytes from young vaccinated horses. Vet. Immunol. Immunopathol. 57, 201214.

[8] Finnish

Food

Authority. https://www.ruokavirasto.fi/yritykset/elainlaakarit/palvelutelainlaakareille/rokoteneuvonta/elainlajikohtaiset-rokotteetja-rokotussuosituksia/hevosrokotteet/ Accessed 1 December 2019.

[9] The Finnish Trotting and Breeding Association (Suomen Hippos).

http://www.hippos.fi/files/24634/Hevostalous_lukuina_201 8.pdf Accessed 24 November 2019

[10] Goyen, K.A., Wright, J.D., Cunneen, A., Henning, J. 2017. Playing with fire - What is influencing horse owners' decisions to not vaccinate their horses against deadly
Hendra virus infection? PLoS One 12: e0180062. doi: 10.1371/journal.pone.0180062

[11] Hautala, K., Näreaho, A., Kauppinen, O., Nielsen, M.K., Sukura, A., Rajala-Schultz, P.J. 2019. Risk factors for equine intestinal parasite infections and reduced efficacy of pyrantel embonate against Parascaris sp. Vet. Parasitol. 273, 52-59.

[12] Horse Information Centre of Finland. Manual of horse owner http://www.hevoseni.fi/madotussuositukset Accessed 23 November 2019.

[13] Koskinen, H.I. 2014a. A survey of horse owners' compliance with the Finnish vaccination program. J. Equine. Vet. Sci. 34, 1114-1117.

[14] Koskinen, H.I. 2014b.Vaccination statistics and reality: how many horses are really vaccinated against equine influenza? J. Agr. Sci. Techn. A. 4, 443-448.

[15] Lind, E.O., Rautalinko, E., Uggla, A., Waller, P.J., Morrison, D.A., Höglund, J. 2007. Parasite control practices on Swedish horse farms. Acta. Vet. Scand. 49, 25.

[16] Lloyd, S., Smith, J., Connan, R.M., Hatcher, M.A., Hedges, T.R., Humphrey, D.J. et al. 2000. Parasite control methods used by horse owners: factors, predisposing to the development of anthelmintic resistance in nematodes. Vet. Rec.146, 487-492.

[17] Luksovsky, J., Craig, T.M., Bingham, G.M., Cyr, T., Forrest, D. 2013.Determining treatment to control two multidrug-resistant parasites on a Texas horse farm. J. Equine. Vet. Sci. 33, 115-119.

[18] van Maanen, C., Bruin, G., de-Boer-Luijitze, E., Smolders, G., de Boer, G.F.1992. Interference of maternal antibodies with the immune response of foals after vaccination against equine influenza. Vet. Q. 14, 13-17.

[19] Manyweathers, J., Field, H., Longnecker, N., Agho, K., Smith, C., Taylor, M. 2017. "Why won't they just vaccinate?" Horse owner risk perception and uptake of the Hendra virus vaccine. BMC. Vet. Res. 13, 103. https://doi.org/10.1186/s12917-017-1006-7

[20] Nielsen, M.K., Monrad, J., Olsen, S.N. 2006. Prescriptiononly anthelmintics - A questionnaire survey of strategies for surveillance and control of equine strongyles in Denmark. Vet. Parasitol. 135, 47-55.

[21] Nielsen, M.K., Reinemayer, C.R., Sellon, D.C. 2014. Nematodes, in: Sellon, D.C, Long M.T. (Eds.), Equine Infectious Diseases, Elsevier, pp. 475-489.

[22] Näreaho, A., Vainio, K., Oksanen, A. 2011. Impaired efficacy of ivermectin against Parascaris equorum, and both ivermectin and pyrantel against strongyle infections in trotter foals in Finland. Vet. Parasitol. 182, 372-377.

[23] Papini, R.A., Micol de Bernart, F., Sgorbini, M. A. 2015. Questionnaire Survey on Intestinal Worm Control Practices in Horses in Italy. J. Equine. Vet. Sci.35, 70-75.

[24] Recommendation of Finnish Veterinary Practitioners. http://www.sep.fi/. Accessed 23 November 2019.

[25] Rendle, D., Austin, C., Bowen, M., Cameron, I., Furtado, T., Hodgkinson, J., et al. 2019. Equine de-worming: a consensus on current best practice. UK-Vet. Equine. 3. https://doi.org/10.12968/ukve.2019.3.S.3 
[26] Ryan, C., Giguére, S. 2010. Equine neonates have attenuated humoral and cell-mediated immune reponses to a killed adjuvanted vaccine compared to adult horses. Clin. Vaccine. Immunol. 17, 1896-1902.

[27] Simoneit, C., McKay-Demeler, J., Merle, R. 2018. Utilization of selective anthelmintic therapy on horse farms in Germany. Tierarztl. Prax. Ausg. Grosstier.e Nutztiere. 46, 87-93.

[28] Stratford, C.H., Lester, H.E., Morgan, E.R., Pickles, K.L., Relf, V., McGorum, B.C. et al. 2014. A questionnaire study of equine gastrointestinal parasite control in Scotland. Equine. Vet. J. 46, 25-31.

[29] Wilson, W.D., Mihalyi, J.E., Hussey, S., Lunn, D.P. 2010. Passive transfer of maternal immunoglobulin isotype antibodies against tetanus and influenza and their effect on the response of foals to vaccination. Equine. Vet. J. 33,644650.

[30] Wilson, W.D., Pusterla, N., Long, M.T. 2014. Immunoprophylaxis, in: Sellon, D.C, Long M.T. (Eds.), Equine Infectious Diseases, Elsevier, pp. 551-570. 